\title{
Use of Antibiotics for Epidermal Wounds in Emergency Room: Correct Prophylaxis and Right Choice of the Treatment
}

\author{
C. Pacioni ${ }^{1,2, *}$, L. Amadori ${ }^{1,2}$, M.S. Hijazi Raed ${ }^{2}$, F. Tosoni ${ }^{2}$ and G. Ricevuti ${ }^{1}$ \\ ${ }^{I}$ Dipartimento di Medicina Interna e Terapia Medica Sezione di Gerontologia e Geriatria, Università degli Studi di \\ Pavia, Italy \\ ${ }^{2}$ U.O. Pronto Soccorso, Istituto Clinico Sant'Anna Brescia, Italy
}

\begin{abstract}
Background: antibiotic therapy and prophylaxis of epidermal wounds in emergency room are often made empirically in case of clinics due to infective complications, although there are no scientific evidences supporting their validity yet. Furthermore, resistance to many antibiotics is a constantly growing problem, especially in Lombardy, Italy. When needed, better prefer beta-lactams or macrolides for their large-spectrum activity.

Methods: We identified all patients (pts) treated to our emergency room for epidermal wounds in a period between 1 st and 31 st july 2012. Then, we performed a retrospective, observational analysis of epidemiological, clinical and therapeutic features of those pts. $\leq 12$ years old individuals were exluded. We considered at high risk of infections pts with at least one of the following comorbidities: diabetes, neoplastic disease, therapy with corticosteroids, immunodepression.

Results: A total of 201 pts were evaluated, 143 males (71.1\%) and 58 females (28.9\%). The median age was 46,3 yrs. Among the pts $101(50.2 \%)$ needed treatment with suture. $13(6.5 \%)$ pts came after at least 12 hrs after the accident. 107 $(53,2 \%)$ pts did not need therapy, while in $82(40.8 \%)$ cases antibiotic prophylaxis $(89 \%$ beta-lactams, $9.8 \%$ macrolides, $1.2 \%$ others ) has been prescribed; $4(2 \%)$ were adviced to start antibiotic therapy only in case of acute epidermal infection development at home; we don't have this information about 8 pts (4\%). In 185 (93.5\%) pts clinical signs of acute epidermal infection were missing. 15 (7.5\%) pts had an high risk of developing infections in history taking; 3 of them received antibiotic prophylaxis, 8 didn't, 4 not known. In 143 individuals $(71,1 \%)$ the history taking has been insufficient.

Conclusions: Even if acute local infection is possible in wounded pts, only subjects at high risk should be closely screened and monitored to detect early infection, in order to evaluate the necessity of specific antibiotic therapy. Clinical evaluation should also include comorbilities as valvulopathy or immunosuppression.
\end{abstract}

Keywords: wound, infection, emergency, antibiotics, prophylaxis, epidermal.

\section{INTRODUCTION}

Simple nonbite wounds are commonly managed in emergency departments [1]; antibiotic therapy and prophylaxis of epidermal wounds are often made empirically in the setting of uncomplicated lacerations, although there is no scientific evidence supporting their validity yet [2]. In fact, whilst the practices of irrigation, debridement, foreign body removal, and suture repair are well accepted, the use of prophylactic antibiotics is not. Without evidenced-based guidelines, practice is left to physician preference [3]. On the other hand, emergency departments are at more risk of malpractice claims due to their quick pace, lack of patient-physician relationships, and patient expectations and demands; it can be assumed that this results in unnecessary, expansive care [4]. Furthermore, resistance to many antibiotics is a constantly

*Address correspondence to these authors at the Dipartimento di Medicina Interna e Terapia Medica Sezione di Gerontologia e Geriatria, Università degli Studi di Pavia, Italy; Tel: 338/7699872; Fax: 338/3197191;

E-mail: perfie@yahoo.com growing problem, especially in Lombardy, Italy; among the population of Lombardy, those who live in our city, Brescia statistically have a significantly higher risk of antibiotic drug exposure [5].

The accurate identification of wound infection provides a clinical challenge to those involved in patient care. Attempts have been made to improve the situation but diverse opinions together with lack of consensus prevail. The literature on infection criteria was reviewed and a set of criteria was collated; a number of criteria at the time were described as subtle in nature and have undergone validation studies [6].

Wounds with the following characteristics can be considered to have a high risk of developing infections: those which come to our attention after more than $12 \mathrm{hrs}$ after their onset, especially if localized on upper limbs; those associated with fractures; those caused by animal bites [7]. These factors can be used to predict the risk of secondary infection of wounds [8]. In those cases, the correct prophylaxis is the administration of a first dose of antibiotics (preferably within 3 hours from the injury occurring), with 3-5 following doses, 


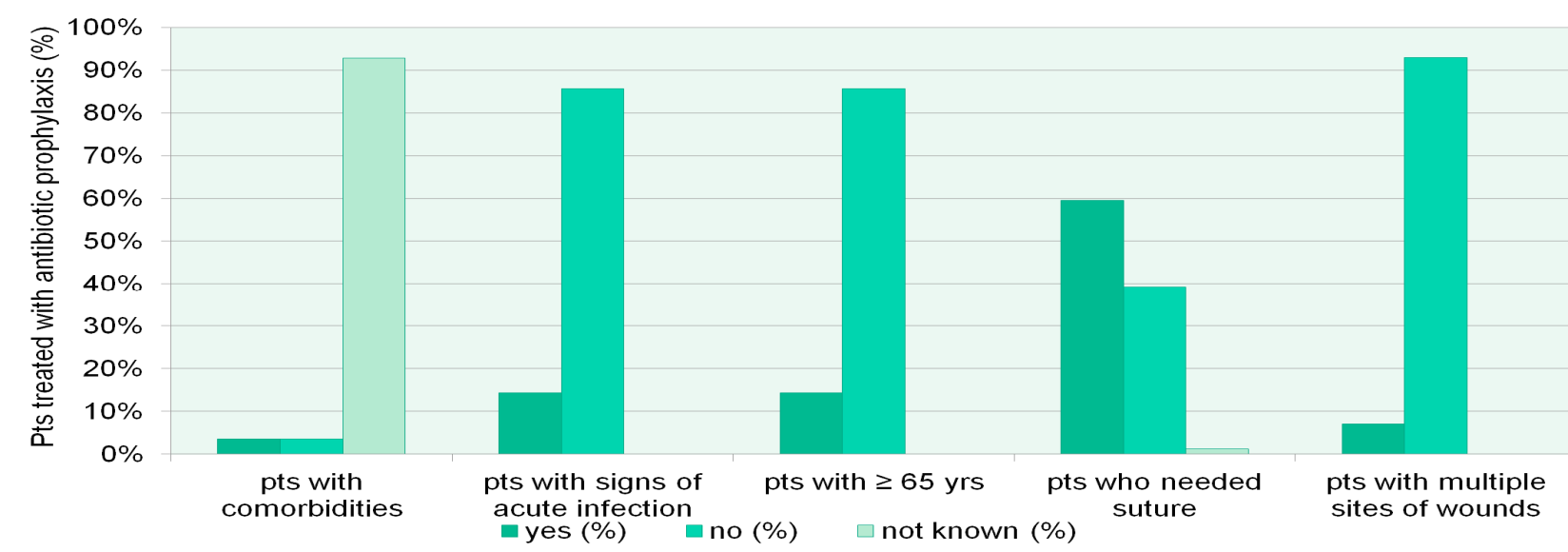

Fig. (1). Characteristics of the 201 pets in study and their relationship with choice of prescribing antibiotic prophylaxis.

choosing a drug active against the most common skin pathogens [7].

\section{MATERIALS AND METHODS}

\subsection{Study Design and Population}

We identified all patients treated at the Department of Emergency of "Istituto Clinico Sant'Anna" in Brescia, Italy, for epidermal wounds in the period between 1st and 31 st july 2012. Then, we performed a retrospective, observational analysis of epidemiological, clinical and therapeutic features of those patients. $\leq 12$ years old individuals were excluded.

Information on demographic parameters (sex, age, history taking) and wound-related characteristics (signs of acute epidermal infection, site of the wound, time spent after the injury happening) at presentation were retrospectively collected.

The aim of this study is to face the constantly growing problem of defensive medicine and to help eradicate it with the use of evidence-based medicine and by ensuring that hospital policies and procedures are followed.

\subsection{Definition of Patients at High Risk of Infections}

We considered patients at high risk of infection with at least one of the following comorbidities found at the time of history taking: diabetes, neoplastic disease, therapy with corticosteroids, immunosuppression [9].

\section{RESULTS}

\subsection{Baseline Characteristics of the Study Population}

During the study period, a total of 201 patients came due to the presence of at least one epidermal wound and was evaluated.

Overall, the majority of patients were male (143/201, $71.1 \%$ ); whereas female patients were 58/201 (28.9\%). The median age was 46,3 years old.

The distribution of the sites of wounds was the following: the majority $(105 / 201,52.2 \%)$ had one wound on the upper limbs, $45 / 201(22.4 \%)$ patients on the lower limbs, 36/201
$(17.9 \%)$ on the head, $1 / 201(0.5)$ on the chest, while $14 / 201$ $(7 \%)$ had more than one wound localized in different sites.

In the majority of the individuals $(143 / 201,71,1 \%)$ the history taking has been insufficient.

$13(6.5 \%)$ patients came after at least $12 \mathrm{hrs}$ after the accident.

\subsection{Management of the Patients in the Emergency Room}

Among the population in study, 105/201 (52,2\%) patients did not received any antibiotic therapy, 4/201 (2\%) were adviced to start antibiotics only in the case of the development of acute epidermal infection at home; we don't have this information about 8/201 (4\%) patients (Fig. 1).

$1 / 201(0.5 \%)$ patient was already taking an antibiotic at home for another motive.

In the remaining $83 / 201(41.3 \%)$ cases, antibiotic prophylaxis had been prescribed: in $73 / 83$ cases $(88 \%)$ the prescription regarded beta-lactams, in $8 / 83$ patients $(9,6 \%)$ macrolides were the first choice, while in the last $1 / 83$ case $(1.2 \%)$ was prescribed fluoroquinolone.

In the majority of the population studied, (185/201, $92 \%$ ), clinical signs of acute epidermal infection were missing; nevertheless, a percentage of $38.4 \%$ ( $71 / 185$ patients) received the prescription of antibiotics to take home.

Among the patients, 101/201 (50.2\%) needed treatment with suture (Fig. 2); 50 (49.5\%) of this subpopulation received an antibiotic prophylaxis. A total of $16(8 \%)$ patients had a high risk of developing infections in history taking; 3 of them received antibiotic prophylaxis, 9 didn't, 4 not known.

All the patients received, when needed, immunoglobulin for tetanus.

\section{DISCUSSION}

In our clinic, we observed 201 patients with at least one wound over the period 1st - 31st July 2012 with no significant differences over time. The greatest percentages of people present with wounds were men, and principally had the site of injury on the upper limbs. The minority of patients came for health care after at least 12 hours after the injury. 


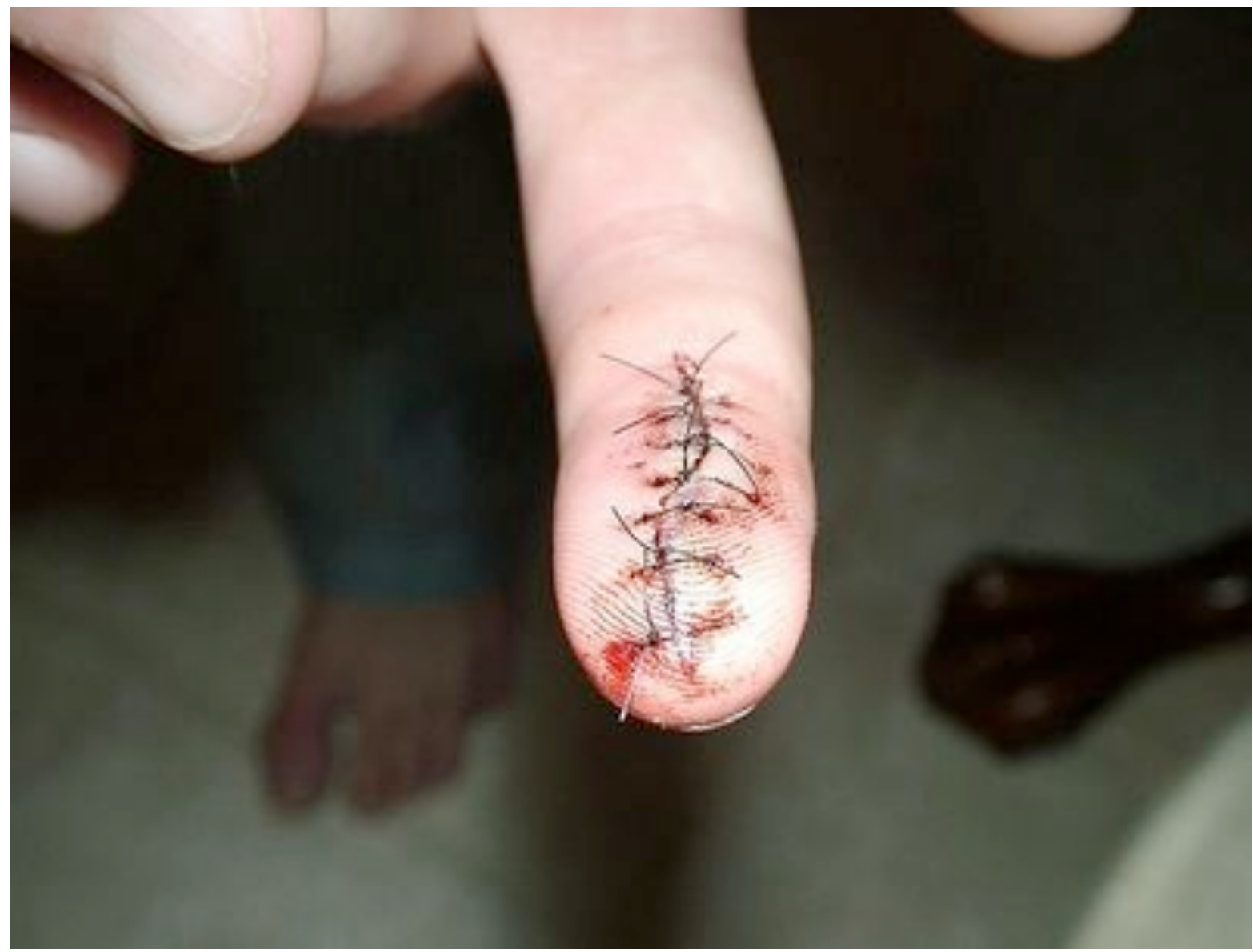

Fig. (2). A wound that needed treatment with suture. Does it show clinical signs of infection?.

On the basis of previous literature findings, we can assert that wounded patients with just one clean wound, with no risk factors in the history taking, display a very low risk of developing an infection.

Nevertheless, almost the half of the population $(41,3 \%)$ in study received an antibiotic prophylaxis despite a lack of evidence for efficacy, according to other recent studies in literature [2]. We could hypothesize that the reason of this over-treatment is about defensive medicine trying to avoid subsequent malpractice claims.

with the greatest percentages of patients not being well investigated about their history taking (we could hypothesize that the reason was in the few minutes that the Emergency Room Medical Doctor can dedicate each patient).

When prescribed, the choice of the antibiotic (betalactams, macrolides, fluoroquinolone) has been in accordance with the aim to use large spectrum antibiotics, active against common skin pathogens.

\section{CONCLUSIONS}

Even if acute local infection is possible in wounded patients, which can be a painful, distressing and have potentially life-threatening complications [10], only subjects at high risk should be closely screened and monitored to detect early infection, in order to evaluate the necessity of a specific antibiotic therapy. The observed differences confirm the need for a careful monitoring with the aim to reduce antibi- otic resistance and improve the rational use of drugs [5]. Clinical evaluation should also include comorbilities as valvulopathy or immunosuppression.

\section{CONFLICT OF INTEREST}

The authors confirm that this article content has no conflicts of interest.

\section{ACKNOWLEDGEMENT}

Declared none.

\section{REFERENCES}

[1] Cummings P, Del Beccaro Ma. Antibiotics to prevent infection of simple wounds: a Meta analysis of randomized studies. Am J Emerg Med 1995; 13(4): 396-400.

[2] Ong S, Moran GJ, Krishnadasan A, et al. Antibiotic prescribing practices of emergency physicians and patient expectations for uncomplicated lacerations. West J Emerg Med 2011; 12(4): 375-80.

[3] Zehtabchi S, Yadav K, Brothers E, et al. Prophylactic antibiotics for simple hand lacerations: time for a clinical trial? Injury 2012; 43(9):1497-501.

[4] Tuers DM. Defensive medicine in the emergency department: increasing health care costs without increasing quality? Nurs Adm Q 2013; 37(2):160-4

[5] Franchi C, Sequi M, Bonati M, et al. Differences in outpatient antibiotic prescription in Italy's Lombardy region. Infection 2011; 39(4): 299-308.

[6] Cutting KF, White RJ. Criteria for identifying wound infectionrevisited. Ostomy Wound Manage 2005; 51(1): 28-34. 
[7] Le ferite in Pronto Soccorso. Programma di formazione a distanza in Medicina d'Urgenza; 2004

[8] Eron LJ. Targeting lurking pathogens in acute traumatic and chronic wounds. J Emerg Med 1999; 17: 189-95.
[9] Principi di best practice: Le ferite infette nella pratica clinica. Un consenso internazionale. Londra: MEP Ltd, 2008

[10] Santy J. Recognising infection in wounds. Nurs Stand 2008; 23(7): $53-4,56,58$ passim.

Received: December 13, 2012

Revised: May 06, 2013

Accepted: May 07, 2013

(C) Pacioni et al.; Licensee Bentham Open.

This is an open access article licensed under the terms of the Creative Commons Attribution Non-Commercial License (http://creativecommons.org/licenses/ by-nc/3.0/) which permits unrestricted, non-commercial use, distribution and reproduction in any medium, provided the work is properly cited. 